\title{
Pregnancy and asymptomatic bacteriuria- A study from a tertiary care teaching hospital, Hyderabad
}

\author{
Yamini Kura $^{1, *}$, Swathi Akula ${ }^{2}$, Sandeep Kumar Tipparthi ${ }^{3}$, HRV Rajkumar ${ }^{4}$ \\ ${ }^{1,2}$ Assistant Professor, ${ }^{3}$ Tutor, ${ }^{4}$ Professor \& HOD, Dept. of Microbiology, Kamineni Academy of Medical Sciences and Research \\ Centre, Hyderabad, Telangana, India
}

*Corresponding Author:

Email: yaminikura@yahoo.in

\begin{abstract}
Introduction: Asymptomatic bacteriuria is found in 2 to $10 \%$ of pregnant women. Complications like acute pyelonephritis, postpartum UTI, hypertension, anemia, prematurity, low birth weight babies and prenatal death may occur if untreated. Hence early detection and treatment are of considerable importance.

Materials and Methods: A crosssectional study was conducted for a period of one year. A clean catch midstream urine sample was collected from pregnant women as a part of routine antenatal screening. The samples were processed according to standard microbiological techniques - wet mount examination, gram staining, glucose test paper, culture and antibiotic susceptibility testing.

Results: Of the 200 samples received from the study group, 28(14\%) were culture positive. The prevalence of culture positivity was more in the third trimester $(19.4 \%)$. The predominant organisms isolated were gram negative bacteria like Escherichia coli $(35.7 \%)$ and Klebsiella spp $(28.5 \%)$. Esch.coli and Klebsiella showed variable resistance to fluoroquinolones, cephalosporins, aminoglycosides, betalactam and betalactam inhibitor combination. However the isolates of Esch.coli were sensitive to carbapenams and polymixins. Isolates of Klebsiella spp were sensitive to Polymixins.

The predictive accuracy of different screening tests with culture was calculated. The sensitivity, specificity, positive predictive value, negative predictive value of grams staining is more compared to urine wet mount examination and urine test paper method in early detection of bacteruria.

Conclusion: Early detection and treatment for asymptomatic bacteriuria is of considerable importance as $40 \%$ of asymptomatic cases develop into pyelonephritis

The choice of antibiotic should be based on urine culture, stage of gestation, clinical data and the characteristics of the antibiotic.
\end{abstract}

Keywords: Asymptomatic bacteriuria, Antenatal women, prevalence, Glucose test paper, Urine culture, Wetmount examination, Gram staining, Perinatal outcomes.

\section{Introduction}

Urinary tract infection (UTI) due to high prevalence, frequent recurrence, legion associated morbidities, and rapidly evolving antimicrobial resistance is one of the most daunting challenges in clinical settings. ${ }^{1}$ UTI are more usual in women ,due to short urethra and easy contamination of urinary tract with fecal flora. ${ }^{2,3}$

In pregnancy, pressure on the ureters by the gravid uterus and the muscle relaxant effect of progesterone, predisposes women with asymptomatic bacteriuria to develop UTI. ${ }^{4}$ Moreover, alteration in $\mathrm{pH}$ of urine and osmolality, glycosuria and aminoaciduria in pregnancy provide an superb culture medium for bacteria to grow. Low socioeconomic status, increasing maternal age, increasing period of gestation, multiparity, are all contributory risk factors associated with escalated prevalence of asymptomatic bacteriuria in pregnancy. ${ }^{5,6}$

Asymptomatic bacteriuria is found in about 2 to $10 \%$ of expecting mothers and the commonest pathogen is Escherichia coli, accounts for about $75-90 \%$ of bacteriuria during pregnancy. ${ }^{7}$ Such women are likely to develop complications like acute pyelonephritis, postpartum UTI, hypertension, anemia, prematurity, low birth weight babies and prenatal death if untreated ${ }^{8,9}$ Hence early detection and treatment are of considerable importance. ${ }^{10}$

Screening for and treating asymptomatic bacteriuria in pregnancy has become a standard of obstetric care and most antenatal guidelines include routine urine screening for asymptomatic bacteriuria. ${ }^{5}$

Hence the present study was undertaken to determine the prevalence, various risk factors and the causative organisms and their antimicrobial susceptibility pattern of asymptomatic bacteriuria among pregnant women attending Outpatient unit of Department of Obstetrics and Gynecology in a tertiary care teaching hospital.

\section{Materials and Methods}

A cross-sectional study was conducted for a period of one year between January -December 2017 in the Department of Microbiology. Institutional ethical clearance was obtained. 200 pregnant women as a part of routine antenatal screening were included in the study population and patients with history of fever $(\geq$ $38^{\circ} \mathrm{c}$ ), those with two or more of the following genitourinary complaints: dysuria, urgency, incontinence, frequency, incomplete voiding, flank/ suprapubic / hypogastric pain were excluded from the study. 
Informed consent was obtained from the study population. Demographic data and detailed history were collected using a pre-structured proforma. Routine antenatal investigations were done.

Clean-catch midstream urine was collected from each patient into a sterile universal container. Samples were processed as per standard loop technique for semiqualitative analysis on dried plates of cysteine lactose electrolyte deficient agar (CLED), using a calibrated drop delivering $0.002 \mathrm{ml}$ of urine. Plates were incubated aerobically of $37^{\circ} \mathrm{C}$ overnight. Colony counts yielding bacterial growth of $10^{5} \mathrm{CFU} / \mathrm{ml}$ or more of pure isolates were regarded as significant for infection. ${ }^{11,12}$

The organisms grown were further identified by routine biochemical reactions and subjected for antimicrobial susceptibility testing by Kirby bauer disc diffusion method. The antibiotics used for Gram positive cocci were Amoxycillin/Clavulanic acid [20/1 Oug], Ampicillin [10 $\mu \mathrm{g}$ ], Cefotaxime [30ug], Cephalexin [30ug], Ciprofloxacin [5ug], Cotrimoxazole [25ug], Linezolid [30ug], Nalidixicacid [30ug], Nitrofurantoin [100ug], Oxacillin [1ug], Vancomycin [30ug].

The antibiotics used for Gram negative bacilli were Amikacin [30ug], Ampicillin [10 $\mu \mathrm{g}$ ], Cefotaxime [30 $\mu \mathrm{g}$ ], Ceftazidime [30 $\mu \mathrm{g}$ ], Ceftriaxone [30ug], Cephalexin [30ug], Ciprofloxacin $[10 \mu \mathrm{g}]$,
Cotrimoxazole [25ug], Nalidixicacid [30ug], Nitrofurantoin [100 $\mu \mathrm{g}]$, Piperacillin / Tazobactam $[100 / 10 \mu \mathrm{g}]$, Meropenam $(30 \mu \mathrm{g})$. The zone of inhibition in mm was interpreted by using CLSI 2017 guidelines. ${ }^{13}$

\section{Results}

Of the 200 samples received from the study group, $28(14 \%)$ were culture positive and $172(86 \%)$ were culture negative. (Fig. 1)

Risk factors having causal relationship with development of asymptomatic UTI are shown in Table I

The prevalence of culture positivity was more in the last trimester (19.4\%) compared to second (11.6\%) and first trimester $(9.5 \%)$.

The predominant organisms isolated were gram negative bacteria like Escherichia coli (35.7\%) and Klebsiella spp (28.5\%). Gram positive bacteria were also isolated but in less number (Table 2)

The antibiogram of the isolates is shown in the Fig. $2 \mathrm{a} \& 2 \mathrm{~b}$.

Among the gram negative bacteria, Esch.coli and Klebsiella showed variable resistance to fluoroquinolones, cephalosporins, aminoglycosides, betalactam and betalactam inhibitor combination. However most of the isolates of Esch.coli were sensitive to carbapenams and polymixins. Isolates of Klebsiella spp were sensitive only to Polymixins.

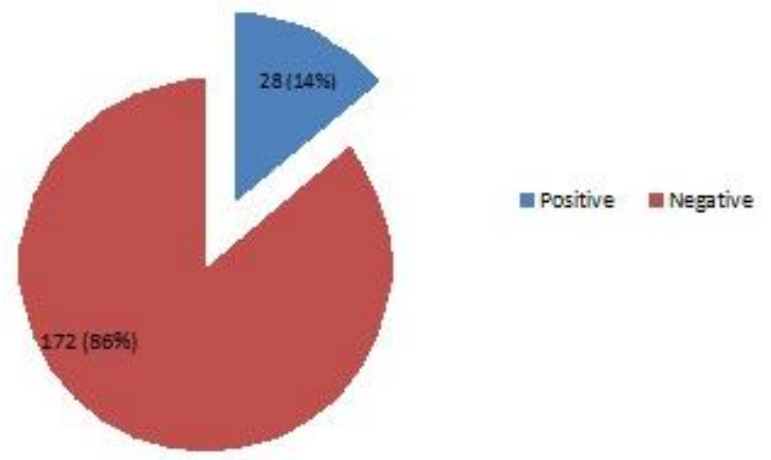

Fig. 1: Prevalence of bacteriuria (Study group $n=200$ )

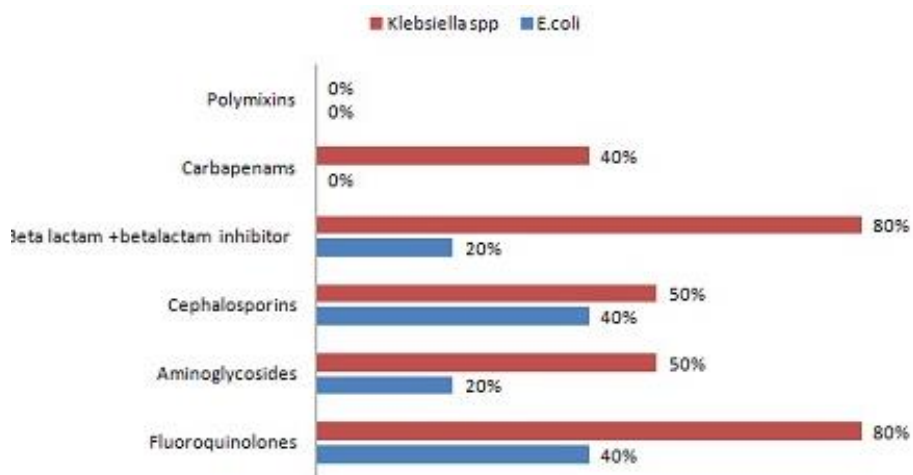

Fig. 2a: Antimicrobial resistance pattern of gramnegative bacilli $(\mathrm{n}=18)$ 


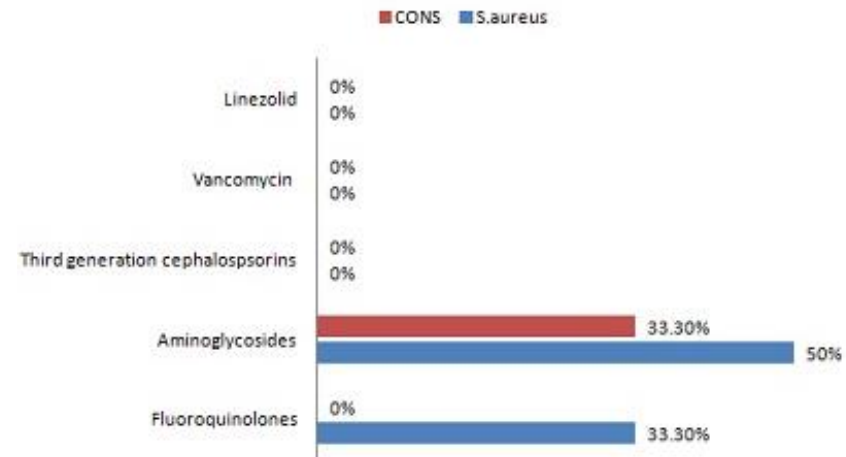

Fig. 2b: Antimicrobial resistance pattern of gram positive cocci $(n=10)$

Table 1: Associated risk factors in pregnant women

\begin{tabular}{|l|c|}
\hline \multicolumn{1}{|c|}{ Risk factors } & $\begin{array}{c}\text { No. of patients with these risk } \\
\text { factors }(\mathbf{n = 2 8})\end{array}$ \\
\hline Anemia & $24(85.7 \%)$ \\
\hline Hypertension & $12(42.8 \%)$ \\
\hline Gestational diabetes & $5(17.8 \%)$ \\
\hline Low socio economic status & $11(39.2 \%)$ \\
\hline
\end{tabular}

Table 2: Uropathogens Isolated

\begin{tabular}{|l|c|}
\hline \multicolumn{1}{|c|}{ Culture } & \multicolumn{1}{|c|}{$\begin{array}{c}\text { No. of Patients with } \\
\text { Significant Bacteriuria(n=28) }\end{array}$} \\
\hline Gram Negative Organisms $(\mathrm{n}=18)$ \\
\hline Escherichia coli & $10(35.7 \%)$ \\
\hline Klebsiella pneumoniae & $8(28.5 \%)$ \\
\hline Gram Postive Organisms (n=10) \\
\hline $\begin{array}{l}\text { Staphylococcus } \\
\text { aureus(C.P.S) }\end{array}$ & $6(21.4 \%)$ \\
\hline $\begin{array}{l}\text { Staphylococcus } \\
\text { saprophyticus(CONS) }\end{array}$ & $4(14.2 \%)$ \\
\hline
\end{tabular}

\section{Discussion}

This study provides the insight about the prevalence of asymptomatic bacteruria among pregnant women attending our hospital and sketch out the associated risk factors, causative organisms and appropriate antimicrobial therapy.

An early detection and treatment of asymptomatic bacteriuria may be of considerable importance not only to preclude acute pyelonephritis and chronic renal failure in the mother, but also to reduce prematurity and fetal mortality in the offspring.

Our study revealed $14 \%$ prevalence of asymptomatic bacteriuria. Review of literature revealed an incidence varying from $4 \%$ to $23.9 \%$ in studies conducted by various workers. Maryam Kasraeian et al, Vaishali et al and Ansari HQ et al reported similar prevalence as the present study. ${ }^{14-16}$ This high prevalence can be attributed to their low socioeconomic status, lack of personal and environmental hygiene. Significant association between presence of bacteriuria and certain risk factors like, low socioeconomic class, lower education level and multiparity have been reported by multiple co workers. ${ }^{17-20}$
Highest prevalence $(22.2 \%)$ recorded in the age group 31-40 years than $18-30$ years $(13.1 \%)$. Nawal et al $(53 \%)$ and Sudha et al $(52 \%)$ have reported similar observations..$^{21,22}$

Elderly females have decrease in glycogen deposition and reduction in the lactobacillus in the genital tract which will facilitate easy adherence of the pathogens and this can contribute as one of the risk factor for acquiring ASB.

Gravida 3 had high prevalence $(17.6 \%)$ than gravida $2(14.2 \%)$ and gravida $1(5.8 \%)$. Humera Qudsia et al (2011) reported high prevalence of asymptomatic bacteriuria among women of gravida 2 (24.19\%) followed by gravida $1(9.76 \%)$, gravida $3(5.83 \%)$, nearly similar to the present study. ${ }^{20}$ The higher incidence of ASB in the multigravida can be attributed to colonization of urinary tract by pathogens due to frequent urinary stasis or due to inadequately treated previous infections.

Culture positivity was more with anaemics $(28.5 \%)$ than non-anaemics (10.1\%). Hypertensives showed more prevalence $(28.5 \%)$ compared to normotensives $(12.9 \%)$. Humera Qudsia et al (2011) also reported high prevalence of asymptomatic bacteriuria among antenatal 
women with anemia (28.57\%) and hypertension $(37.50 \%)$ similar to the present study. ${ }^{20}$ The predominant organism isolated was Escherichia coli (35.7\%) followed by Klebsiella pneumoniae $(28.5 \%)$, Staphylococcus aureus (21.4\%), Staphylococcus saprophyticus (14.2\%).

The predominant organism isolated was Escherichia coli as reported by several studies. ${ }^{23-27}$ Antibiogram of Gram negative organisms showed highest sensitivity to Carbapenams followed by beta lactam and beta lactam inhibitor combination, Nitrofurantoin, third generation cephalosporins, Aminoglycosides and fluoroquinolones. Antibiogram of Gram positive organisms showed highest sensitivity to Vancomycin, Linezolid, Teicoplanin and moderate resistance to aminoglycosides and fluoroquinolones.

In our study, the quite a good proportion of the isolates were susceptible to Nitrofurantoin. Studies from Bangladesh and Ghana have similar observation. ${ }^{28,29}$

The choice of antibiotic should be based on urine culture, stage of gestation, clinical data and the characteristics of the antibiotic. ASB in pregnancy is generally treated with oral cephalexin and nitrofurantoin due to high urinary concentration. Complicated cases are treated with parenteral antibiotics. ${ }^{30}$

\section{Conclusion}

Asymptomatic bacteriuria is common in pregnancy but its prevalence varies widely with age, gender, and the presence of genitourinary abnormalities or underlying diseases. Screening, isolation and identification with antimicrobial testing has to be advised for pregnant women with asymptomatic bacteriuria because of the risk of progression to severe symptomatic urinary tract infection and possible harm to the fetus. The choice of antibiotic should be based on urine culture, stage of gestation, clinical data and the characteristics of the antibiotic. An active interaction between a Clinician and a Clinical Microbiologist will combat the complications maternal and foetal complications.

Funding: No funding sources.

Conflict of interest: None declared.

\section{References}

1. Michael J. Droller, MD.Urologic issues for the Internist. Med Clin N Am 2011;90(1):27.

2. Gupta K, Sahm DF, Mayfield D, Stamm WE. Antimicrobial resistance among uropathogens that cause community acquired urinary tract infections in women: a nationwide analysis. Clin Infect Dis 2001;3:89-94.

3. Al-Dujiaily AA. Urinary tract infection during pregnancy in Tikrit. Med J Tikrit 2000;6:220-24.

4. Duarte G, Marcolin AC, Quintana SM, Cavalli RC. Urinary tract infection in pregnancy. Rev Bras Ginecol Obstet 2002;30(2):93-100.

5. American Academy of Pediatrics, American College of Obstetricians and Gynaecologists: Guidelines for perinatal care, $5^{\text {th }}$ edition, 2002.

6. Maranchie JK, Capelouto CC, Loughlin KR. Urinary tract infections during pregnancy. Infect Urol 1997;10:152-57.
7. Hankins GD, Whalley PJ. Acute urinary tract infections in pregnancy. Clin Obstet Gynaecol 1985;28:266-78.

8. Etherington, J. and James, D.K. Reagent strip testing of antenatal urine specimens for infection. Br J Obstet Gynaecol 1993;100:806-8.

9. Millar, L, Debuque, L, Leialoha, C, Grandinetti, A. and Killeen, J. Rapid enzymatic urine screening test to defect bacteriuria in pregnancy. Obstet Gynecol 2000;95:601-4.

10. Gayathree L, Shetty S, Deshpande SR, Venkatesh DT. Screening for asymptomatic bacteriuria in pregnancy. An evaluation of various screening tests in Hassan District Hospital, India. JCDR 2010; 4(4):2702-6.

11. J.G. Collee, A.G. Fraser, B.P. Marmion, A. Simmons, Mackie \& McCartney, Practical Medical Microbiology, $14^{\text {th }}$ edition, 2006; 85 .

12. Betty A. Forbes, Daniel F. Sahm, Alice S. Weissfeld, Bailey \& Scott's, Diagnostic Microbiology, $12^{\text {th }}$ edition, 2007; 842.

13. CLSI.Performance standards for antimicrobial susceptibility testing. $27^{\text {th }}$ Ed.CLSI supplement $M$ 100.Wayne PA. Clinical and laboratory standards institute; 2017.

14. Kasraeian M. Prevalence of asymptomatic bactetiuria among pregnant women in Shiraz. Iran Saudi Med J 2009;30(7):917-20.

15. Ansari HQF, Rajkumari A. Prevalence of asymptomatic bacteriuria and associated risk factors among antenatal women attending a tertiary care hospital. J Med Allied Sci 2001;1(2):74-8.

16. Jain V, Das V, Agarwal A, Pandey A. Asymptomatic bacteriuria and obstetric outcome following treatment in early versus late pregnancy in north Indian women. Indian J Med Res 2013;137(4):753.

17. Kovavisarach E, Vichaipruck M, Risk factors related to asymptomatic bacteriuria in pregnant women. J Med Assoc Thai 2009;92(5):606-10.

18. Goldaber K. Urinary tract infection during pregnancy. Infect Urol 1997;10:152-7.

19. Girishbabu RJ. Asymptomatic bacteriuria in pregnancy. Int J Biol Med Res 2011;2(3):740-2.

20. Qudsia H. Prevalence of asymptomatic bacteruria and associated risk factors among antenatal women attending a tertiary care hospital. J Med Allied Sci 2011;1(2):74-8.

21. Al Senani NS. Asymptomatic bacteriuria in pregnant women. Bahrain Med Bull 2011;33:1-4.

22. Sudha Biradar K, Rajeshwari S, Sheela S Sagarad, Sneha Hegadi. Asymptomatic bacteriuria among pregnant women. Int J Reprod Contracept Obstet Gynecol 2013;2(2):213-6

23. Hazhir S. Asymptomatic bacteriuria in pregnant women. Urol J (Tehran) 2007;4:24-7.

24. Selimuzzaman ABM. Asymptomatic bacteriuria during pregnancy: Causative agents and their sensitivity in Rajshahi city. J Teachers Assoc 2006;19(2):66-9.

25. Ahmed S. Prevalence of asymptomatic bacteriuria among pregnant women in Kashmir. SLCOG 2011;33:158-62.

26. Anayet Ullah M. Prevalence of asymptomatic bacteriuria and its consequences in pregnancy in a rural community of Bangladesh. Bangladesh Med Res Counc Bull 2007;33:604.

27. Enayat K. Asymptomatic bacteriuria among pregnant women referred to outpatient clinics in Sanandaj. Iran Int Braz J Urol 2008; 34(6):699-707.

28. Khattak AM. Antimicrobial sensitivity pattern of urine isolates from asymptomatic bacteriura during pregnancy. E:/Biomedica. 2006; 22.

29. Institute of Medicine. Preventing Low Birth weight. Washington, DC: National Academy Press 1985:46-93 
30. John E. Delzell and Michael L. Lefevre. Urinary Tract Infections During Pregnancy. Am Fam Physician 2000;61(3):713-20.

How to cite this article: Kura Y., Akula S., Tipparthi S., H. Rajkumar. Pregnancy and asymptomatic bacteriuria- A study from a tertiary care teaching hospital, Hyderabad. Int J Med Microbiol Trop Dis 2018;4(4):181-85. 